\title{
Patients treated with radical prostatectomy with positive digital rectal examination findings in the intermediate-risk group are prone to PSA recurrence
}

\author{
NOBUKI FURUBAYASHI ${ }^{1}$, TAKAHITO NEGISHI ${ }^{1}$, SHINTARO URA $^{1}$, JUN MUTAGUCHI $^{1}$, \\ KENICHI TAGUCHI ${ }^{2}$, MOTOTSUGU SHIMOKAWA ${ }^{3}$ and MOTONOBU NAKAMURA ${ }^{1}$ \\ Departments of ${ }^{1}$ Urology and ${ }^{2}$ Pathology; ${ }^{3}$ Institute for Clinical Research, \\ National Kyushu Cancer Center, Fukuoka 811-1395, Japan
}

Received February 5, 2015; Accepted March 1, 2016

DOI: $10.3892 / \mathrm{ol} .2016 .4485$

\begin{abstract}
The present study aimed to evaluate the possibility of performing radical prostatectomy (RP) alone to achieve a radical cure for prostate cancer in the intermediate-risk group. Samples were collected from 638 Japanese patients who underwent antegrade RP between August 1998 and May 2013; subsequently, 157 patients were excluded. According to the D'Amico criteria, the low-, intermediate- and high-risk groups comprised 107, 222 and 152 patients, respectively. The 5-year prostate-specific antigen (PSA) failure-free survival rates in the low-, intermediate-, and high-risk groups were 96.5, 88.9 and $72.6 \%$, respectively $(\mathrm{P}<0.001$; degrees of freedom $=2)$. In the intermediate-risk group, the difference in PSA failure-free survival between the $0<\mathrm{PSA} \leq 10$ and $10<\mathrm{PSA} \leq 20 \mathrm{ng} / \mathrm{ml}$, and the biopsy Gleason score 6 and 7 groups were not statistically significant, according to the log-rank test $(\mathrm{P}=0.2266$ and $\mathrm{P}=0.1329$, respectively). However, the difference in PSA failure-free survival between the clinical tumor stage (cT)1c and cT2a/b groups was statistically significant based on the log-rank test $(\mathrm{P}<0.0001)$. The results of the multivariate analysis revealed that, of the preoperative characteristics, only the cT was a significant predictor in patients with and without PSA failure $(\mathrm{P}<0.001)$. Therefore, patients classified into the intermediate-risk group with cT2a/b stage, according to positive digital rectal examination findings, and are not considered to be likely to achieve a complete cure with RP surgery alone. In summary, for patients meeting these criteria in the intermediate-risk group, RP surgery alone is likely to be insufficient, and other additional treatments may be considered subsequent to RP.
\end{abstract}

Correspondence to: Dr Nobuki Furubayashi, Department of Urology, National Kyushu Cancer Center, 3-1-1 Notame, Minami-ku, Fukuoka 811-1395, Japan

E-mail: furubayashi.n@nk-cc.go.jp

Key words: prostate cancer, radical prostatectomy, intermediate-risk, prostate-specific antigen recurrence, digital rectal examination

\section{Introduction}

Prostate cancer varies from insignificant lesions to locally advanced prostate tumors, even in cases without distant metastasis $(1,2)$. Thus, it is necessary to develop a finer stage classification system in order to determine the most appropriate therapy for patients with prostate cancer that require more treatment options.

Diagnostic imaging is not as useful for prostate cancer as it is for other malignant tumors. Although digital rectal examination (DRE), ultrasound and magnetic resonance imaging are commonly used to evaluate the clinical tumor stage (cT), these diagnostic imaging modalities lack accuracy (3-5). By contrast, the prostate-specific antigen (PSA) level is an excellent tumor marker available for prostate cancer diagnosis (6). In addition, the grade of the tumor (Gleason score) can be determined using a prostate needle biopsy (7). Therefore, the disease stage is classified using multiple factors. The risk classification of prostate cancer corresponds with this concept, with the D'Amico classification being the most widely used (8). According to the D'Amico criteria, for convenience, the intermediate-risk group includes patients with cT2b lesions, a biopsy Gleason score (bGS) of 7 or a PSA level of $>10$ to $\leq 20 \mathrm{ng} / \mathrm{ml}$. In the D'Amico classification, cases that do not belong to the low-risk or high-risk groups are also assigned to the intermediate-risk group. As a result, the breadth of cases included in the intermediate-risk group is wide.

In the low-risk group, there is a high probability that prostate cancer is localized in the prostate, and this group is considered most likely to achieve a cure with radical prostatectomy (RP) alone. By contrast, RP for patients in the low-risk group also presents the possibility of over-treatment (9). Conversely, in the high-risk group, radiation therapy in combination with endocrine therapy is common $(10,11)$; however, there is no reason not to treat with RP (12). There is a high possibility, although lower than for the low-risk group, that RP will achieve a cure in the intermediate-risk group. When considering the control of cancer and postoperative quality of life, the intermediate-risk group may receive the most benefit from surgery. 
Therefore, the present study assessed the outcomes of radical prostatectomy (RP) in Japanese intermediate-risk patients with prostate cancer who received no pre-surgical treatment. The possibility of achieving a complete cure with RP alone was evaluated.

\section{Patients and methods}

Patient characteristics and risk-group classification. Patients who underwent prostate biopsies and received a diagnosis of adenocarcinoma at the National Kyushu Cancer Center (Fukuoka, Japan) or additional associated institutions were assessed in the present study. Embedded whole-mount antegrade RP tissue specimens obtained from 638 patients who underwent RP between August 1998 and May 2013 were evaluated. The patients underwent pelvic lymph node dissection during the same time period. Of the specimens obtained, 157 patients were excluded from the study, including 151 patients due to a history of receiving hormonal therapy and 6 patients due to unclear biopsy or prostatectomy specimen findings. All patients were Japanese (median age, 66 years; range, 47-77 years), and the PSA levels ranged between 0.623 and $39.413 \mathrm{ng} / \mathrm{ml}$ (median, $7.491 \mathrm{ng} / \mathrm{ml}$ ). The median follow-up period after surgery was 54.1 months.

The patients were classified into three risk groups according to the D'Amico criteria (3). The low-risk (stage T1c/T2a, PSA level $\leq 10 \mathrm{ng} / \mathrm{ml}$ and $\mathrm{bGS}$ of $\leq 6$ ), intermediate-risk (stage T2b, bGS of 7 or PSA level between $>10$ and $\leq 20 \mathrm{ng} / \mathrm{ml}$ ) and high-risk (stage T2c, PSA level $>20 \mathrm{ng} / \mathrm{ml}$ or bGS of $\geq 8$ ) groups comprised 107 (22.2\%), $222(46.2 \%)$ and $152(31.6 \%)$ patients, respectively. The breadth of cases included in the intermediate-risk group was wide, therefore, the patients were subdivided according to factors for risk classification, including the PSA level, cT status and bGS. The PSA levels were divided into two subgroups of $0<\mathrm{PSA} \leq 10$ and $10<\mathrm{PSA} \leq 20$, the cT status was divided into two subgroups of cT1c and cT2a, and the bGS score was divided into two subgroups of bGS 6 and bGS 7. cT was diagnosed using only DRE. Two pathologists evaluated the degree of malignancy in the preoperative biopsy and RP specimens according to the 2005 International Society of Urological Pathology Consensus Conference on Gleason grading system (13) and determined the pathological stage based on the 2009 TNM classification (14).

Methods. The whole-organ prostate specimens obtained by RP were fixed in $15 \%$ neutral-buffered formalin (Wako Pure Chemical Industries, Ltd., Osaka, Japan) for 48-96 h, and were serially sectioned perpendicular to the rectal surface at 5-mm intervals. Sections that were predominantly caudal and cephalic were cut in the sagittal plane at 5-mm intervals in order to assess the bladder neck and apical margins. The specimens were subsequently embedded in paraffin (Merck KGaA, Darmstadt, Germany), cut into $5-\mu \mathrm{m}$ sections and stained with hematoxylin and eosin (Sakura Finetek Japan, Co., Ltd., Tokyo, Japan). Extraprostatic extension (EPE) was defined as the extension of the tumor from the prostate to the periprostatic soft tissue. The presence of tumor cells at the stained resection margin (RM) was defined as a positive RM. The follow-up schedule after RP involved a PSA assay performed using ARCHITECT ${ }^{\circledR}$ Automated Immunoassay Analyzer,
ARCHITECT Total PSA Calibrators (catalog no., 7K70-01) and ARCHITECT Total PSA Controls (catalog no., 7k70-10) (Abbott Japan Co., Ltd., Chiba, Japan) every 3 months for the first 2 years, followed by every 4 months for the next 3 years and every 6 months thereafter. Disease recurrence and/or PSA failure were defined as the detection of a serum PSA level of $>0.2 \mathrm{ng} / \mathrm{ml}$, or the use of RP if the PSA level did not decrease to $<0.2 \mathrm{ng} / \mathrm{ml}$ following surgery. A number of patients who underwent RP were subsequently treated with radiation and/or hormone therapy before the serum PSA level exceeded $0.2 \mathrm{ng} / \mathrm{ml}$. Therefore, in these patients, the time point of adjuvant therapy was defined as the date of disease recurrence. All patients provided their written informed consent to participate in this study, and the study protocol was approved by the ethics committee of the National Kyushu Cancer Center.

Statistical analysis. Statistical analysis was performed using the JMP Pro software package (version 11.0.0; SAS Institute, Inc., Cary, NC, USA). The PSA failure-free survival rate was determined according to the Kaplan-Meier method, and the significance of clinicopathological parameters associated with PSA failure was assessed using the Cox proportional hazards regression model. The log-rank test was used to determine differences between the risk groups. $\mathrm{P}<0.05$ was considered to indicate a statistically significant difference.

\section{Results}

Clinicopathological characteristics according to risk group. The clinicopathological characteristics of the three risk groups are shown in Table I. According to the D'Amico criteria, the low-risk group, intermediate-risk group and high-risk group each contained 107 (22.2\%), 222 (46.2\%) and 152 (31.6\%) patients, respectively. No differences were observed in the age of the patients between the groups. Based on the RP Gleason score, $9.3 \%$ (10/107), $15.3 \%$ (34/222) and 42.1\% (64/152) of the patients in the low-, intermediate- and high-risk groups had high-grade (bGS $\geq 8$ ) tumors, respectively. A total of $17.8 \%$ $(19 / 107), 35.1 \%(78 / 222)$ and $54.0 \%(82 / 152)$ of patients in the low-, intermediate- and high-risk groups had a pathological stage of $\geq \mathrm{T} 3$, respectively. Furthermore, lymph node involvement was observed in 1 patient in the low-risk group, 5 patients in the intermediate-risk group and 7 patients in the high-risk group.

PSA failure-free survival rates according to the risk group classification. The 5-year PSA failure-free survival rates in the low-, intermediate- and high-risk groups were 96.5, 88.9 and $72.6 \%$, respectively (Fig. 1). The difference between the low- and intermediate-risk groups was statistically significant, according to the log-rank test $(\mathrm{P}=0.0113)$. In addition, the difference between the intermediate- and high-risk groups was statistically significant, according to the log-rank test $(\mathrm{P}=0.0004)$.

Correlations between clinicopathological characteristics and PSA failure in the intermediate-risk group. The correlations between clinicopathological characteristics and PSA failure in the intermediate-risk group are shown in Table II. According to Cox proportional hazards analysis in this group, cT was the 
Table I. Clinicopathological characteristics according to the risk group classification.

\begin{tabular}{|c|c|c|c|}
\hline \multirow[b]{2}{*}{ Characteristic } & \multicolumn{3}{|c|}{ Risk group } \\
\hline & Low & Intermediate & High \\
\hline Total patients, $\mathrm{n}$ & 107 & 222 & 152 \\
\hline Median age (range), years & $66(47-77)$ & $66(57-76)$ & $67(48-77)$ \\
\hline \multicolumn{4}{|l|}{$\mathrm{cT}, \mathrm{n}(\%)$} \\
\hline $1 \mathrm{c}$ & $84(78.5)$ & $157(70.7)$ & $77(50.7)$ \\
\hline $2 \mathrm{a} / \mathrm{b}$ & $23(21.5)$ & $65(29.3)$ & $47(30.9)$ \\
\hline $2 \mathrm{c}$ & - & - & $21(13.8)$ \\
\hline 3 & - & - & $7(4.6)$ \\
\hline \multicolumn{4}{|l|}{ Preoperative PSA, n (\%) } \\
\hline$\leq 10 \mathrm{ng} / \mathrm{ml}$ & $107(100)$ & $151(68.1)$ & $83(54.6)$ \\
\hline $10 \leq 20 \mathrm{ng} / \mathrm{ml}$ & - & $71(31.9)$ & $36(23.7)$ \\
\hline$>20 \mathrm{ng} / \mathrm{ml}$ & - & - & $33(21.7)$ \\
\hline \multicolumn{4}{|l|}{ Biopsy Gleason score, n (\%) } \\
\hline$\leq 6$ & $107(100)$ & $19(8.6)$ & $8(5.2)$ \\
\hline 7 & - & $203(91.4)$ & $27(17.8)$ \\
\hline$\geq 8$ & - & - & $117(77.0)$ \\
\hline \multicolumn{4}{|l|}{ RP Gleason score, n (\%) } \\
\hline$\leq 6$ & $45(42.1)$ & $18(8.2)$ & $6(3.4)$ \\
\hline 7 & $52(48.6)$ & $170(76.5)$ & $82(53.9)$ \\
\hline$\geq 8$ & $10(9.3)$ & $34(15.3)$ & $64(42.1)$ \\
\hline \multicolumn{4}{|l|}{$\mathrm{pT}, \mathrm{n}(\%)$} \\
\hline $2 a / b$ & $18(16.8)$ & $27(12.2)$ & $9(5.9)$ \\
\hline $2 c$ & $70(65.4)$ & $117(52.7)$ & $61(40.1)$ \\
\hline $3 a$ & $17(15.9)$ & $71(32.0)$ & $64(42.1)$ \\
\hline $3 b$ & $2(1.9)$ & $7(3.1)$ & $18(11.9)$ \\
\hline EPE, n (\%) & 17 (15.9) & $66(29.7)$ & $65(42.8)$ \\
\hline Positive RM, n (\%) & $13(12.1)$ & $45(20.3)$ & $35(23.0)$ \\
\hline $\mathrm{sv}, \mathrm{n}(\%)$ & $2(1.9)$ & $7(3.2)$ & $18(11.8)$ \\
\hline $\mathrm{pN}, \mathrm{n}(\%)$ & $1(0.9)$ & $5(2.3)$ & $7(4.6)$ \\
\hline
\end{tabular}

Clinical and pathological staging was based on the 2009 TNM classification; Gleason grading based on the 2005 International Society of Urological Pathology Consensus Conference. $\mathrm{P}<0.05$ was considered to indicate a statistically significant difference. cT, clinical tumor stage; PSA, prostate-specific antigen; RP, radical prostatectomy; pT, pathological tumor stage; EPE, extraprostatic extension; RM, resection margin; $\mathrm{sv}$, seminal vesicle invasion; $\mathrm{pN}$, pathological lymph node metastasis.

only preoperative variable that was a significant predictor of PSA failure $(\mathrm{P}<0.001)$, whereas the postoperative variables of RP Gleason score, pathological tumor stage, EPE, seminal vesicle invasion and positive lymph nodes were found to be significant predictors, based on the univariate analysis.

In the multivariate analysis, statistically significant differences were observed for the cT stage $(\mathrm{P}<0.001)$ and seminal vesicle invasion $(\mathrm{P}=0.003)$ in the patients with and without PSA failure.

PSA failure-free survival rates according to PSA subgroups in the intermediate-risk group (Fig. 2). Based on the range of the PSA level, the intermediate-risk group was divided into two subgroups with values of $0<\mathrm{PSA} \leq 10$ and $10<\mathrm{PSA} \leq 20 \mathrm{ng} / \mathrm{ml}$. A value of $10<\mathrm{PSA} \leq 20 \mathrm{ng} / \mathrm{ml}$ was identified in $31.9 \%(71 / 222)$ of the patients. The 5-year PSA failure-free survival rates in the $0<\mathrm{PSA} \leq 10$ and $10<\mathrm{PSA} \leq 20 \mathrm{ng} / \mathrm{ml}$ groups were 91.7 and $82.5 \%$, respectively, although the difference between these groups was not statistically significant according to the log-rank test $(\mathrm{P}=0.2266)$.

PSA failure-free survival rates according to the bGS subgroups in the intermediate-risk group (Fig. 3). Based on the bGSs, the intermediate-risk group was divided into two subgroups of bGS 6 and 7. A bGS of 6 was identified in only 8.6\% (19/222) of the patients, and there were no cases of PSA failure $(100 \%$ 5-year PSA failure-free survival). The 5-year PSA failure-free survival rate in the bGS 7 group was $87.9 \%$, and the difference between the bGS 6 and bGS 7 groups was not statistically significant according to the log-rank test $(\mathrm{P}=0.1329)$. 
Table II. Correlations between the clinicopathological characteristics and PSA failure in the intermediate-risk group.

\begin{tabular}{|c|c|c|c|}
\hline Variable & Hazard ratio & P-value & $95 \% \mathrm{CI}$ \\
\hline \multicolumn{4}{|l|}{ Univariate analysis } \\
\hline Age, $<70$ vs. $\geq 70$ years $^{a}$ & 1.180 & 0.705 & $0.518-3.022$ \\
\hline PSA, 0-10 vs. $>10-20 \mathrm{ng} / \mathrm{ml}^{\mathrm{a}}$ & 1.625 & 0.242 & $0.709-3.551$ \\
\hline $\mathrm{cT}, 1 \mathrm{c}$ vs. $2 \mathrm{a} / \mathrm{b}^{\mathrm{a}}$ & 10.274 & $<0.001$ & $4.350-28.227$ \\
\hline RP Gleason score, $\leq 7$ vs. $\geq 8$ & 3.188 & 0.010 & $1.354-7.020$ \\
\hline pT, 2 vs. 3 & 3.627 & 0.001 & $1.653-8.516$ \\
\hline EPE, 0 vs. 1 & 3.240 & 0.003 & $1.470-7.240$ \\
\hline RM, 0 vs. 1 & 1.198 & 0.703 & $0.438-2.816$ \\
\hline sv, 0 vs. 1 & 6.378 & 0.006 & $1.834-17.017$ \\
\hline pN, 0 vs. 1 & 18.860 & $<0.001$ & $4.207-62.156$ \\
\hline \multicolumn{4}{|l|}{ Multivariate analysis } \\
\hline Age, $<70$ vs. $\geq 70$ years $^{\mathrm{a}}$ & 1.655 & 0.245 & $0.718-4.279$ \\
\hline PSA, $0-10 \mathrm{vs} .>10-20 \mathrm{ng} / \mathrm{ml}^{\mathrm{a}}$ & 1.237 & 0.636 & $0.494-2.872$ \\
\hline $\mathrm{cT}, 1 \mathrm{c}$ vs. $2 \mathrm{a} / \mathrm{b}^{\mathrm{a}}$ & 11.481 & $<0.001$ & $4.754-32.310$ \\
\hline RP Gleason score, $\leq 7$ vs. $\geq 8$ & 1.728 & 0.237 & $0.684-4.074$ \\
\hline pT, 2 vs. 3 & 2.349 & 0.068 & $1.001-5.717$ \\
\hline EPE, 0 vs. 1 & 2.252 & 0.061 & $1.033-5.063$ \\
\hline RM, 0 vs. 1 & 1.614 & 0.334 & $0.581-3.875$ \\
\hline sv, 0 vs. 1 & 8.538 & 0.003 & $2.383-24.473$ \\
\hline pN, 0 vs. 1 & 2.914 & 0.199 & $0.529-12.559$ \\
\hline
\end{tabular}

aPreoperative variable. Clinical and pathological staging was based on the 2009 TNM classification system; Gleason grading based on the 2005 International Society of Urological Pathology Consensus Conference. $\mathrm{P}<0.05$ was considered to indicate a statistically significant difference. PSA, prostate-specific antigen; cT, clinical tumor stage; RP, radical prostatectomy; pT, pathological tumor stage; EPE, extraprostatic extension; RM, resection margin; sv, seminal vesicle invasion; $\mathrm{pN}$, pathological lymph node metastasis; 0 , negative; 1 , positive; $\mathrm{CI}$, confidence interval.

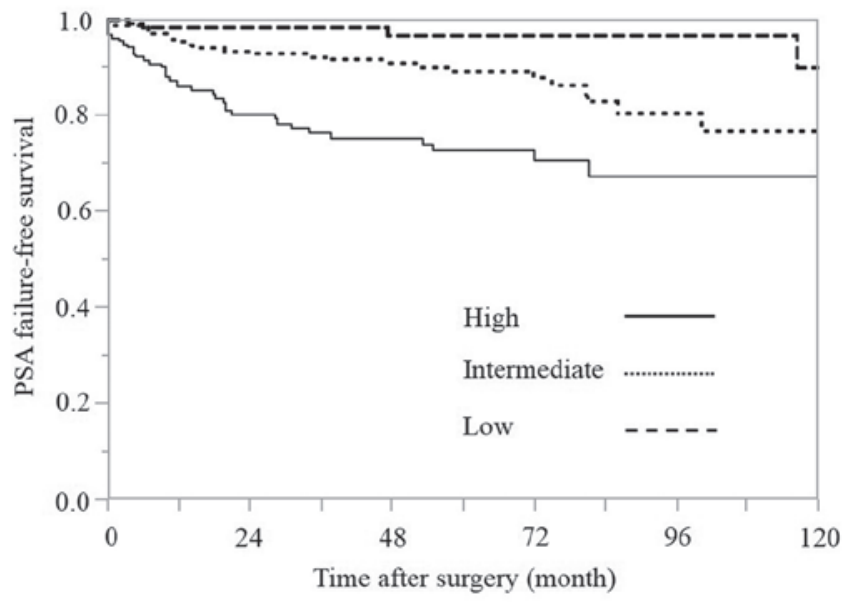

Figure 1. Kaplan-Meier estimates of PSA failure-free survival according to the risk group $(\mathrm{P}<0.001$; degrees of freedom=2). PSA, prostate-specific antigen.

PSA failure-free survival rates based on the primary Gleason pattern in the bGS 7 subgroup within the intermediate-risk group (Fig. 4). In the intermediate-risk group, a bGS of 7 was identified in $91.4 \%(203 / 222)$ of the patients, and bGSs of $3+4$ and $4+3$ were identified in 128 and 74 patients, respectively. Only 1 patient had a bGS of 5+2. The 5-year PSA failure-free survival rates in the bGS $3+4$ and $4+3$ groups were 92.7 and $79.9 \%$, respectively, and the difference between the bGS $3+4$ and $4+3$ groups was statistically significant according to the log-rank test $(\mathrm{P}=0.0298)$.

PSA failure-free survival rates according to the cT subgroups in the intermediate-risk group (Fig. 5). The cT was diagnosed using only DRE. In the intermediate-risk group, a cT $2 \mathrm{a} / \mathrm{b}$ status was identified in $29.3 \%(65 / 222)$ of the patients. The 5-year PSA failure-free survival rates in the cT1c and cT2a/b groups were 94.0 and $76.4 \%$, respectively, and the difference between the cT1c and cT2a/b groups was statistically significant according to the log-rank test $(\mathrm{P}<0.0001)$.

\section{Discussion}

$\mathrm{RP}$ is selected as a treatment for prostate cancer to achieve a cure by resecting the cancer lesion. However, depending on the patient's clinical condition, it may be difficult to resect the prostate cancer completely and/or distant metastasis may develop even if the entire local prostate tumor is successfully resected. This treatment is considered to be successful if the postoperative PSA level remains stable at a low value. Therefore, it is understood that RP should be performed in cases with a low likelihood of PSA recurrence. However, surgical intervention may result in overtreatment when the indication 


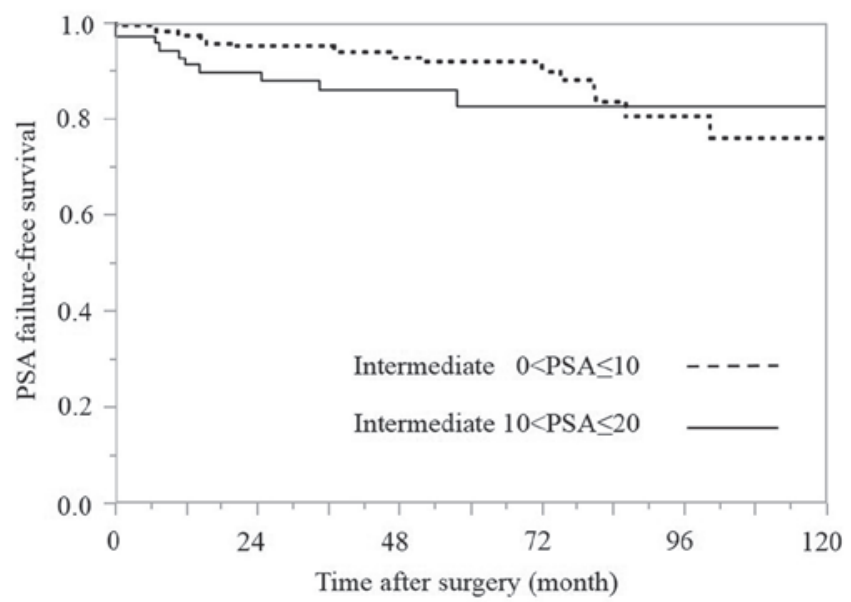

Figure 2. Kaplan-Meier estimates of PSA failure-free survival rates according to the PSA groups in the intermediate-risk group $(\mathrm{P}=0.227$; degrees of freedom=1). PSA, prostate-specific antigen.

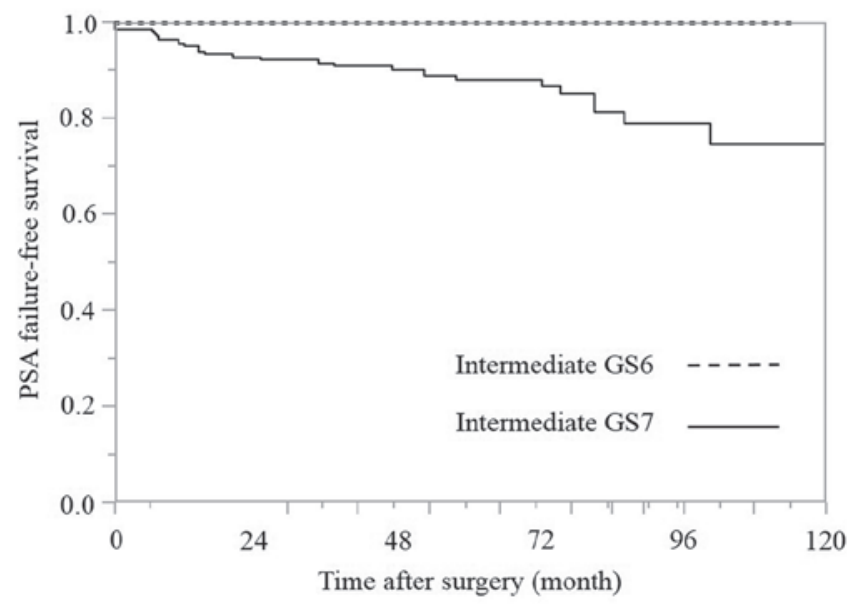

Figure 3. Kaplan-Meier estimates of PSA failure-free survival according to the biopsy GS groups in the intermediate-risk group $(\mathrm{P}=0.133$; degrees of freedom=1). PSA, prostate-specific antigen; bGS, biopsy Gleason score.

for surgery is limited to only patients whose clinical condition is not likely to lead to PSA failure, as other treatments are expected to have equivalent outcomes, and certain types of prostate cancer may be monitored with active surveillance or a 'watchful waiting' strategy.

According to the 2012 version of the clinical practice guidelines for prostate cancer in Japan (15), RP is recommended for patients who are not expected to develop PSA recurrence, such as those with a bGS $\leq 7$, a PSA level of $<10 \mathrm{ng} / \mathrm{ml}$ and a cT of cT1c-T2c. This guideline is based on the results of a variety of prognostic studies with large RP samples (16-19), although these studies were retrospective. However, there is no definitive reason as to why RP is should not be used, even in high-risk cases of PSA recurrence (20-23). In other words, a complete cure with surgery alone is possible in these cases.

In patients with prostate cancer, as in other malignancies, it is important to assess the degree of malignancy and determine the prognosis in order to select the appropriate treatment. Risk classification, the grouping of patients based on several clinical factors, is widely used in the clinical setting. Several

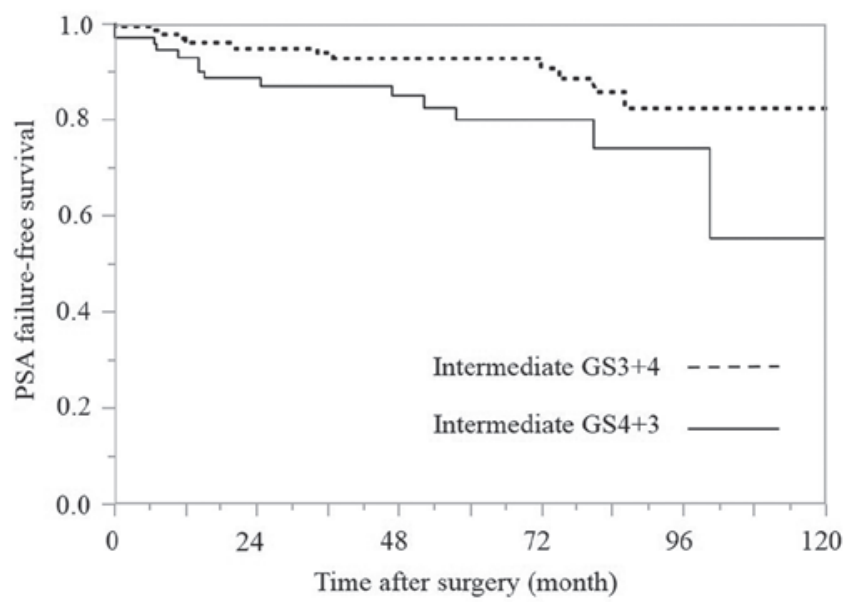

Figure 4. Kaplan-Meier estimates of PSA failure-free survival based on the primary Gleason pattern in the biopsy GS 7 group within the intermediate-risk group $(\mathrm{P}=0.030$; degrees of freedom=1). PSA, prostate-specific antigen; GS, Gleason score.

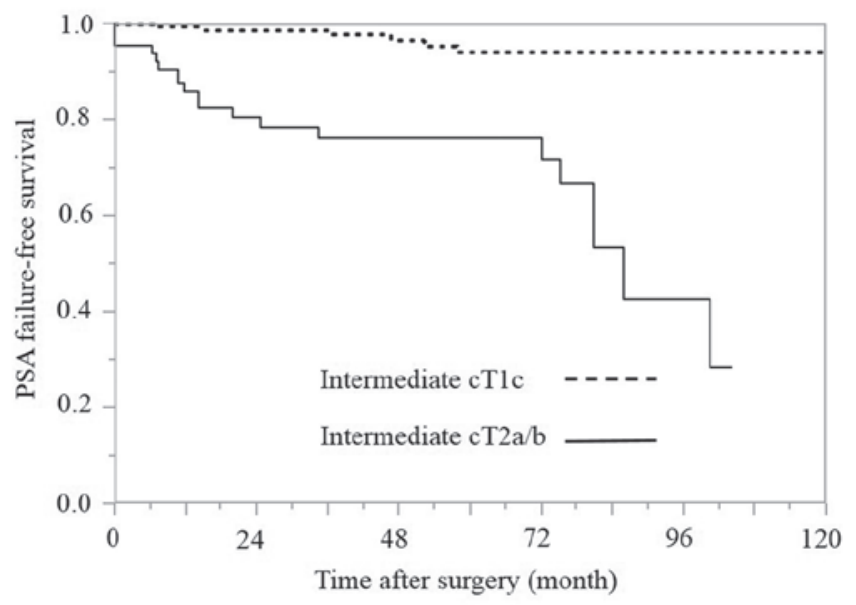

Figure 5. Kaplan-Meier estimates of PSA failure-free survival according to the cT groups in the intermediate-risk group $(\mathrm{P}<0.001$; degrees of freedom $=1)$. PSA, prostate-specific antigen; cT, clinical tumor stage.

pre-treatment risk classification models for prostate cancer have been proposed to date, with the D'Amico classification being the most widely applied (8). However, in the D'Amico classification, cases that do not belong to the low-risk or high-risk groups are assigned to the intermediate-risk group. Hence, the range of cases included in the intermediate-risk group is wide.

Therefore, the present study aimed to assess the outcomes of RP in intermediate-risk Japanese patients who received no pre-surgical treatment in order to investigate the possibility of achieving a complete cure with RP alone. According to the D'Amico criteria, indicated in Table I, the low-, intermediate- and high-risk group each contained 107 (22.2\%), $222(46.2 \%)$ and $152(31.6 \%)$ patients, respectively. Based on the bGS, high-grade (bGS $\geq 8$ ) tumors were only noted in patients in the high-risk group (77.0\%; 117/152); by comparison, high-grade RP Gleason scores were observed in $9.3 \%$ (10/107), $15.3 \%(34 / 222)$ and $42.1 \%(64 / 152)$ of the patients in the low-, intermediate- and high-risk groups, respectively, 
which emphasizes that high-grade Gleason scores may be present in a proportion of patients of in the intermediate-risk group.

The present study determined the cT classification based on only the results of the DRE, in accordance with the original study by D'Amico et al (8). The PSA failure-free survival rates for each risk group are shown in Fig. 1. The 5-year PSA failure-free survival rates in the low-, intermediate- and high-risk groups were $96.5,88.9$ and $72.6 \%$, respectively (Fig. 1). The difference between the intermediate- and high-risk groups $(\mathrm{P}=0.0004)$, and the difference between the intermediate- and low-risk groups $(\mathrm{P}=0.0113)$ were statistically significant according to the log-rank test. The results indicate that the rate of a complete cure with RP alone in the intermediate-risk group was lower than that observed in the low-risk group and higher than that observed in the high-risk group.

In addition, correlations between clinicopathological characteristics and PSA failure were examined in the intermediate-risk group (Table II). There were no cases of PSA failure among the bGS 6 cases, therefore, the preoperative variable of bGS was not analyzed in the univariate or multivariate Cox proportional hazards regression model. According to the results of multivariate analysis, cT was the only significant predictor in the patients with and without PSA failure $(\mathrm{P}<0.001)$ among the preoperative variables. Univariate and multivariate analyses did not reveal any other statistically significant differences in the preoperative variables, including the preoperative PSA level $(\mathrm{P}=0.242)$, which is a component of the risk profile in the D'Amico risk classification. The postoperative variables of RP Gleason score, pathological tumor stage, EPE and positive lymph nodes were found to be significant predictors based on the univariate analysis $(\mathrm{P}=0.010, \mathrm{P}=0.001, \mathrm{P}=0.003$ and $\mathrm{P}<0.001$, respectively), while the only postoperative variable identified to be a significant predictor in the univariate and multivariate analyses was seminal vesicle invasion $(\mathrm{P}=0.006$ and $\mathrm{P}=0.003$, respectively). However, the intermediate-risk group included only cases that did not belong to the low- or high-risk groups; as a result, the breadth of cases included in the intermediate-risk group was unexpectedly wide. Therefore, additional analyses were performed in the intermediate-risk group, including factors used for risk stratification, such as the PSA level, bGS and cT status.

First, the patients were divided into two groups based on the PSA values: $0<\mathrm{PSA} \leq 10$ and $10<\mathrm{PSA} \leq 20 \mathrm{ng} / \mathrm{ml}$ (Fig. 2). Values of $0<\mathrm{PSA} \leq 10$ and $10<\mathrm{PSA} \leq 20 \mathrm{ng} / \mathrm{ml}$ were identified in $68.1 \%(151 / 222)$ and $31.9 \%(71 / 222)$ of the patients, respectively. Pathological organ-confined disease is known to occur in $80 \%$ of patients with a PSA level $<4.0 \mathrm{ng} / \mathrm{ml}, 66 \%$ of those with a PSA level between 4.0 and $10.0 \mathrm{ng} / \mathrm{ml}$ and $<50 \%$ of those with a PSA level $>10.0 \mathrm{ng} / \mathrm{ml}(24,25)$. Therefore, it is expected that the rate of organ-confined disease decreases as the PSA value increases and, thus, the risk of recurrence increases. Compared with that observed in the low-risk group, the intermediate-risk group demonstrated a wide range of PSA values according to the D'Amico risk classification. However, the 5-year PSA failure-free survival rates in the $0<\mathrm{PSA} \leq 10$ and $10<\mathrm{PSA} \leq 20 \mathrm{ng} / \mathrm{ml}$ groups were 91.7 and $82.5 \%$, respectively, and the difference between the $0<\mathrm{PSA} \leq 10$ and $10<\mathrm{PSA} \leq 20 \mathrm{ng} / \mathrm{ml}$ groups was not statistically significant according to the log-rank test $(\mathrm{P}=0.2266)$.
Next, the patients were divided into two groups based on the bGS: bGS 6 and bGS 7 (Fig. 3). bGS 6 was identified only in $8.6 \%(19 / 222)$ of the patients and bGS 7 was identified in $91.4 \%(203 / 222)$ of the patients. There were no episodes of PSA failure in the bGS 6 group (PSA failure-free survival rate, $100 \%$ ), and the 5-year PSA failure-free survival rate in the bGS 7 group was $87.9 \%$. The difference between the bGS 6 and 7 groups was not statistically significant according to the log-rank test $(\mathrm{P}=0.1329)$. This result is considered to be a contributory factor to the lack of PSA failure among bGS 6 cases. Furthermore, the bGS 7 pattern is additionally considered to be a contributory factor, as the intermediate-risk group consisted largely of patients with a bGS 7 score. According to the bGS 7 pattern in the intermediate-risk group, the bGS $3+4$ and 4+3 subgroups contained $128(63.1 \%)$ and $74(36.5 \%)$ patients, and the bGS $5+2$ subgroup contained 1 patient. In the present study, among all of the bGS7 cases, excluding the single case of bGS 5+2, the 5-year PSA failure-free survival rates in the bGS $3+4$ and $4+3$ groups were 92.7 and $79.9 \%$, respectively (Fig. 4). The difference between the bGS $3+4$ and $4+3$ groups was statistically significant according to the log-rank test $(\mathrm{P}=0.0298)$.

Although numerous grading systems exist for evaluating prostate adenocarcinoma, the Gleason grading system is the most widely accepted (26). The Gleason system is based on the glandular pattern of the tumor, as identified at relatively low magnification; cytological features have no role in the grade of the tumor. The primary (predominant) and secondary (second most prevalent) architectural patterns are identified and assigned a grade between 1 and 5, with 1 being the most differentiated and 5 being the least differentiated. As both the primary and secondary patterns are influential for predicting the prognosis, the Gleason sum score is obtained by adding the primary and secondary grades. It is important to recognize Gleason pattern 4 tumors, as tumors with this pattern are associated with a significantly worse prognosis than those with pure Gleason pattern $3(27,28)$. It has also been demonstrated in RP specimens that tumors with a Gleason score of $4+3=7$ exhibit a worse prognosis than those with a Gleason score of $3+4=7$ (29). These descriptions are consistent with the observations made in the present study.

Finally, the patients in the present study were divided into two groups based on the cT status: cT1c and cT2a/b. cT1c and cT2a/b was identified in $70.7 \%(157 / 222)$ and $29.3 \%(65 / 222)$ of the patients, respectively. Numerous imaging modalities are applied for staging prostate cancer; however, no technique is reliably sensitive for detecting extraprostatic disease. The inability to image microscopic disease limits the accuracy of current modalities (30). In the current study, the cT classification was determined based only on the results of DRE, in accordance with the original study by D'Amico et al (8). The 5-year PSA failure-free survival rates in the clinical cT1c and cT2a/b groups were 94.0 and $76.4 \%$, respectively (Fig. 5), and the difference between the cT1c and cT2a/b groups was statistically significant according to the log-rank test $(\mathrm{P}<0.0001)$. An abnormal DRE was recently reported to be associated with an increased risk of detecting high-grade (Gleason score $>7$ ) prostate cancer lesions in a screened population (31-34). These descriptions are consistent with the observations obtained in the present study. 
In summary, the present study retrospectively assessed the outcomes of performing RP alone in Japanese patients with intermediate-risk prostate cancer based on the D'Amico risk classification. Patients classified into the intermediate-risk group with cT $2 \mathrm{a} / \mathrm{b}$ stage, based on positive DRE findings, are not considered to be likely to achieve a complete cure with RP surgery alone. Furthermore, the current findings for intermediate-risk group RP patients demonstrated that tumors with a bGS of $4+3=7$ are associated with poorer PSA failure-free survival rates than those with a bGS of $3+4=7$ in the bGS 7 group. Therefore, for patients meeting these criteria in the intermediate-risk group, RP surgery alone is likely to be insufficient, and other additional treatments may be considered subsequent to RP.

\section{References}

1. Cooperberg MR, Broering JM and Carroll PR: Time trends and local variation in primary treatment of localized prostate cancer. J Clin Oncol 28: 1117-1123, 2010.

2. Wilt TJ, Brawer MK, Jones KM, Barry MJ, Aronson WJ, Fox S, Gingrich JR, Wei JT, Gilhooly P, Grob BM, et al; Prostate Cancer Intervention versus Observation Trial (PIVOT) Study Group: Radical prostatectomy versus observation for localized prostate cancer. N Engl J Med 367: 203-213, 2012.

3. Rifkin MD: MRI of the prostate. Crit Rev Diagn Imaging 31: 223-262, 1990

4. Tempany CM, Zhou X, Zerhouni EA, Rifkin MD, Quint LE, Piccoli CW, Ellis JH and McNeil BJ: Staging of prostate cancer: Results of Radiology Diagnostic Oncology Group project comparison of three MR imaging techniques. Radiology 192: 47-54, 1994.

5. Wolf JS Jr, Cher M, Dall'era M, Presti JC Jr, Hricak H and Carroll PR: The use and accuracy of cross-sectional imaging and fine needle aspiration cytology for detection of pelvic lymph node metastases before radical prostatectomy. J Urol 153: 993-999, 1995

6. Oesterling JE, Jacobsen SJ, Klee GG, Pettersson K, Piironen T, Abrahamsson PA, Stenman UH, Dowell B, Lövgren T and Lilja H: Free, complexed and total serum prostate specific antigen: The establishment of appropriate reference ranges for their concentrations and ratios. J Urol 154: 1090-1095, 1995.

7. Epstein JI, Allsbrook WC Jr, Amin MB and Egevad LL; ISUP Grading Committee: The 2005 International Society of Urological Pathology (ISUP) consensus conference on Gleason grading of prostatic carcinoma. Am J Surg Pathol 29: 1228-1242, 2005.

8. D'Amico AV, Whittington R, Malkowicz SB, Schultz D, Blank K, Broderick GA, Tomaszewski JE, Renshaw AA, Kaplan I, Beard CJ and Wein A: Biochemical outcome after radical prostatectomy, external beam radiation therapy, or interstitial radiation therapy for clinically localized prostate cancer. JAMA 280: 969-974, 1998.

9. Smith JA Jr: Radical prostatectomy for low risk carcinoma of the prostate. World J Urol 26: 443-446, 2008.

10. Bolla M, Collette L, Blank L, Warde P, Dubois JB, Mirimanoff RO, Storme G, Bernier J, Kuten A, Sternberg C, et al: Long-term results with immediate androgen suppression and external irradiation in patients with locally advanced prostate cancer (an EORTC study): a phase III randomised trial. Lancet 360: 103-106, 2002.

11. D'Amico AV, Manola J, Loffredo M, Renshaw AA, DellaCroce A and Kantoff PW: 6-month androgen suppression plus radiation therapy vs radiation therapy alone for patients with clinically localized prostate cancer: a randomized controlled trial. JAMA 292: 821-827, 2004

12. Pierorazio PM, Ross AE, Lin BM, Epstein JI, Han M, Walsh PC, Partin AW, Pavlovich CP and Schaeffer EM: Preoperative characteristics of high-Gleason disease predictive of favourable pathological and clinical outcomes at radical prostatectomy. BJU Int 110: 1122-1128, 2012

13. Epstein JI, Allsbrook WC Jr, Amin MB and Egevad LL; ISUP Grading Committee: The 2005 International Society of Urological Pathology (ISUP) consensus conference on Gleason grading of prostatic carcinoma. Am J Surg Pathol 29: 1228-1242, 2005.
14. Sobin LH, Gospodarowicz MK and Wittekind Ch (eds): Urological Tumors. In: TNM Classification of Malignant Tumors. 7th edition. Wiley-Blackwell, Oxford, pp243-248, 2009.

15. The Japanese Urological Association (eds): Surgical Therapy. In: Clinical Practice Guidelines for Prostate Cancer in Japan. 2012 version. Kanehara-shuppan Press, Tokyo, pp115-117 2012.

16. Roehl KA, Han M, Ramos CG, Antenor JA and Catalona WJ: Cancer progression and survival rates following anatomical radical retropubic prostatectomy in 3,478 consecutive patients: Long-term results. J Urol 172: 910-914, 2004

17. Porter CR, Kodama K, Gibbons RP, Correa R Jr, Chun FK, Perrotte P and Karakiewicz PI: 25-year prostate cancer control and survival outcomes: A 40-year radical prostatectomy single institution series. J Urol 176: 569-574, 2006.

18. Isbarn H, Wanner M, Salomon G, Steuber T, Schlomm T, Köllermann J, Sauter G, Haese A, Heinzer H, Huland H and Graefen M: Long-term data on the survival of patients with prostate cancer treated with radical prostatectomy in the prostate-specific antigen era. BJU Int 106: 37-43, 2010.

19. Suardi N, Porter CR, Reuther AM, Walz J, Kodama K, Gibbons RP, Correa R, Montorsi F, Graefen M, Huland H, et al: A nomogram predicting long-term biochemical recurrence after radical prostatectomy. Cancer 112: 1254-1263, 2008.

20. Carver BS, Bianco FJ Jr, Scardino PT and Eastham JA: Long-term outcome following radical prostatectomy in men with clinical stage T3 prostate cancer. J Urol 176: 564-568, 2006.

21. Gontero P, Marchioro G, Pisani R, Zaramella S, Sogni F, Kocjancic E, Mondaini N, Bonvini D, Tizzani A and Frea B: Is radical prostatectomy feasible in all cases of locally advanced non-bone metastatic prostate cancer? Results of a single-institution study. Eur Urol 51: 922-929, 2007.

22. Van Poppel H and Joniau S: An analysis of radical prostatectomy in advanced stage and high-grade prostate cancer. Eur Urol 53: 253-259, 2008

23. Miocinovic R, Berglund RK, Stephenson AJ, Jones JS, Fergany A, Kaouk J and Klein EA: Avoiding androgen deprivation therapy in men with high-risk prostate cancer: The role of radical prostatectomy as initial treatment. Urology 77: 946-950, 2011

24. Catalona WJ,Smith DS and Ornstein DK: Prostate cancer detection in men with serum PSA concentrations of 2.6 to $4.0 \mathrm{ng} / \mathrm{ml}$ and benign prostate examination. Enhancement of specificity with free PSA measurements. JAMA 277: 1452-1455, 1997.

25. Rietbergen JB, Hoedemaeker RF, Kruger AE, Kirkels WJ and Schröder FH: The changing pattern of prostate cancer at the time of diagnosis: Characteristics of screen detected prostate cancer in a population based screening study. J Urol 161: 1192-1198, 1999.

26. Gleason DF and Mellinger GT: Prediction of prognosis for prostatic adenocarcinoma by combined histological grading and clinical staging. J Urol 111: 58-64, 1974

27. McNeal JE, Villers AA, Redwine EA, Freiha FS and Stamey TA: Histologic differentiation, cancer volume, and pelvic lymph node metastasis in adenocarcinoma of the prostate. Cancer 66: 1225-1233, 1990

28. Epstein JI, Pizov G and Walsh PC: Correlation of pathologic findings with progression after radical retropubic prostatectomy. Cancer 71: 3582-3593, 1993.

29. Chan TY, Partin AW, Walsh PC and Epstein JI: Prognostic significance of Gleason score $3+4$ versus Gleason score $4+3$ tumor at radical prostatectomy. Urology 56: 823-827, 2000.

30. Wein AJ, Kavoussi LR, Novick AC, Partin AW, Peters CA and Ramchandani P: Prostate cancer tumor markers. In: Campbell-Walsh urology tenth edition review. McDougal SW (ed). 10th edition. Elsevier Saunders, Philadelphia, PA, pp2748-2770, 2011.

31. Gosselaar C, Roobol MJ, Roemeling S and Schröder FH: The role of the digital rectal examination in subsequent screening visits in the European randomized study of screening for prostate cancer (ERSPC), Rotterdam. Eur Urol 54: 581-588, 2008.

32. Borden LS Jr, Wright JL, Kim J, Latchamsetty K and Porter CR: An abnormal digital rectal examination is an independent predictor of Gleason $>$ or $=7$ prostate cancer in men undergoing initial prostate biopsy: A prospective study of 790 men. BJU Int 99: 559-563, 2007.

33. Okotie OT, Roehl KA, Han M, Loeb S, Gashti SN and Catalona WJ: Characteristics of prostate cancer detected by digital rectal examination only. Urology 70: 1117-1120, 2007.

34. Thompson IM, Ankerst DP, Chi C, Goodman PJ, Tangen CM, Lucia MS, Feng Z, Parnes HL and Coltman CA Jr: Assessing prostate cancer risk: Results from the prostate cancer prevention trial. J Natl Cancer Inst 98: 529-534, 2006. 